\title{
Subacute ruminal acidosis and total mixed ration preference in lactating dairy cows ${ }^{1}$
}

\author{
D. D. Maulfair, K. K. Mclntyre, and A. J. Heinrichs ${ }^{2}$ \\ Department of Animal Science, The Pennsylvania State University, University Park 16802
}

\begin{abstract}
Subacute ruminal acidosis (SARA) is a condition where the $\mathrm{pH}$ of the rumen becomes abnormally acidic because of increased and altered production of volatile fatty acids. The objective of this experiment was to determine how a SARA challenge affects total mixed ration selection in dairy cows. In this study, 8 multiparous, lactating, ruminally cannulated Holstein cows were given a choice between a long-forage-particle-size diet with slow-fermenting starch (LC) and a shortforage-particle-size diet with fast-fermenting starch in a crossover design. Cows were allowed to adapt to this feeding scheme and were then subjected to a rumen challenge to induce a bout of SARA. The rumen challenge successfully decreased rumen $\mathrm{pH}$ and altered rumen volatile fatty acid profiles. Daily average rumen $\mathrm{pH}$ decreased from 6.02 to 5.77 , and average minimum rumen $\mathrm{pH}$ decreased from 5.59 to 5.28. In addition, following the rumen challenge, concentrations of acetate, butyrate, and valerate, and acetate-to-propionate ratio increased. In response to the rumen challenge, intake of LC increased from the baseline level of $18.1 \%$ of total daily dry matter intake to $38.3 \%$ for that day. During the first recovery day after the rumen challenge, LC intake moderated to $28.0 \%$ of total daily dry matter intake. On the second recovery day, LC intake returned to baseline levels at $18.6 \%$. These results indicate that cows are able to alter their diet preference for higher physically effective fiber and slower starch fermentability during a bout of SARA and that they can effectively fully recover from this type of SARA within $72 \mathrm{~h}$ when appropriate diets are available.
\end{abstract}

Key words: acidosis, diet selection, particle size, sorting

\footnotetext{
Received March 7, 2013.

Accepted June 26, 2013.

${ }^{1}$ This research was a component of NC-1042, Management Systems to Improve the Economic and Environmental Sustainability of Dairy

${ }^{2}$ Corresponding author: ajh@psu.edu
} Enterprise.

\section{INTRODUCTION}

Subacute ruminal acidosis is a major concern in the modern high-producing dairy cow. It is defined as a moderately depressed rumen $\mathrm{pH}$ in the range of 5.5 to 5.0 (Nocek, 1997; Krause and Oetzel, 2006). Krause and Oetzel (2006) suggested that 3 major causes of SARA exist in dairy herds: excessive intake of rapidly fermentable carbohydrates, inadequate ruminal adaptation to a highly fermentable diet, and inadequate ruminal buffering caused by inadequate dietary fiber or inadequate physical fiber. The negative effects of SARA are vast and varied; ranging from decreased DMI (Britton and Stock, 1987; Nocek, 1997) and reduced feed efficiency (Huntington, 1993; Nocek, 1997) to decreased milk fat yield (Nocek, 1997) and contributing to lameness (Nocek, 1997; NRC, 2001; Stone, 2004). A study that evaluated 154 cows in 14 Wisconsin dairy herds determined that $20.1 \%$ of lactating cows had SARA when tested using rumenocentesis (Oetzel et al., 1999). In a case study of a 500-cow dairy in central New York State, Stone (1999) estimated that SARA could cost up to $\$ 475 /$ cow per year in lost milk production and components only. Clearly, SARA warrants extensive research and management.

Several studies have examined diet and feed selection changes when sheep or lambs were subjected to acidotic rumen conditions. For example, in a study by Phy and Provenza (1998b), lambs were fed a meal of rolled barley and then offered a choice of flavored (onion or oregano) rabbit pellets that either contained $\mathrm{NaHCO}_{3}$ and lasalocid or $\mathrm{NaCl}$. The authors determined that after a grain meal, lambs preferred rabbit pellets that contained $\mathrm{NaHCO}_{3}$ and lasalocid over pellets that contained $\mathrm{NaCl}$. Another study by Phy and Provenza (1998a) examined the effect that eating a meal of rapidly fermentable feed had on the preference for rapidly fermentable feed later in the day. Lambs fed a lower amount $(400 \mathrm{~g})$ of rolled barley for a meal exhibited equal preference for rolled barley and alfalfa pellets ( 52 and $48 \%$ of total intake respectively) during the next 4 h. However, when a higher amount $(1,200 \mathrm{~g})$ of rolled barley was fed, the lambs increased their preference for alfalfa pellets over rolled barley (71 and $29 \%$ of total 
intake, respectively) during this same time (Phy and Provenza, 1998a). All of these results show that lambs prefer feeds that attenuate acidosis after a grain meal to maintain ruminal health.

In addition, studies have examined the influence of SARA in dairy cows on eating behavior. Keunen et al. (2002) conducted an experiment where $25 \%$ of DMI of cows being fed a TMR was replaced by wheat and barley pellets to induce SARA. The choice of 2 feeds (long alfalfa hay and alfalfa pellets) was then offered 2 times per day for $30 \mathrm{~min}$ each. Cows with SARA increased their consumption of long alfalfa hay over alfalfa pellets compared with their consumption without SARA; 85 and $60 \%$ of test feeds were consumed as long alfalfa hay for SARA and non-SARA cows, respectively (Keunen et al., 2002). DeVries et al. (2008) used a rumen challenge model to induce SARA in early and midlactation Holstein cows. The rumen challenge consisted of restricting feed to $50 \%$ of ad libitum DMI for $1 \mathrm{~d}$ and then feeding $4 \mathrm{~kg}$ of barley and wheat, after which cows had ad libitum access to TMR. Changes in eating behavior were measured by determining the particle size distribution of offered feed and refusals and calculating a selection index for each particle fraction. After the rumen challenge, cows in both groups changed their sorting behavior. DeVries et al. (2008) determined that early lactation cows generally increased their sorting for medium particles and against short and fine particles and exhibited no change in sorting long particles. Midlactation cows exhibited variable responses with sorting activity changing with day and period. DeVries et al. (2008) suggested that both early and mid-lactation cows altered their sorting behavior to consume a diet that would help attenuate their bout of SARA.

Despite evidence of dairy cattle altering their eating behavior or diet choice based on their rumen environment, no research has been published where cattle had access to 2 distinct diets to observe the influence of SARA on diet preference and eating behavior. Therefore, the objective of this experiment was to induce a bout of SARA in lactating dairy cows that had ad libitum access to 2 distinct diets that varied in forage particle size and starch fermentability and to determine how SARA affects TMR selection in dairy cows.

\section{MATERIALS AND METHODS}

\section{Diets, Cows, and Experimental Design}

Cows used in this research were cared for and maintained according to a protocol approved by The Pennsylvania State University Institutional Animal Care and Use Committee (University Park). Eight lactating, multiparous, ruminally cannulated, Holstein cows averaging $219 \pm 61 \mathrm{DIM}$ and $44 \pm 7 \mathrm{~kg}$ of milk production/d, weighing $702 \pm 56 \mathrm{~kg}$, and with parity of $3.13 \pm 0.99$ (mean $\pm \mathrm{SD}$ ) were studied. The trial consisted of two 7-d adaptation periods, followed by 8-d collection periods in a crossover design.

For the duration of the study, cows were fed 2 different diets simultaneously: a long-particle-size-diet with slowly fermentable starch (LC) and a short-particlesize-diet with fast starch fermentability (SF). Diets were offered to cows in tie-stall feed bunks divided into halves via a plywood panel that eliminated crosscontamination of TMR. The side of the feed bunk that the diets were offered was alternated each day to limit the possibility for bias of bunk location or relationship to water bowls. The 2 rations fed contained identical ingredients and proportions, but varied in the particle length of corn silage and the particle size of dry ground corn. The LC diet included long corn silage (LCSLG) and dry cracked corn (CC) and the SF diet included short corn silage (SCSLG) and dry fine ground corn (FC). Ingredients and their percentage of ration DM were corn silage (42.6), dry ground corn (22.2), alfalfa haylage (15.4), canola meal (9.4), roasted split soybeans (7.1), mineral/vitamin mix (2.5), salt (0.4), and Optigen (Alltech Inc., Nicholasville, KY; 0.4).

The corn silage hybrid was Pioneer 34M78 (Pioneer Hi-Bred International Inc., Johnston, IA) that was planted on April 19, 2010, and harvested on August 30, 2010. Corn silage was harvested with a John Deere 6750 forage harvester (John Deere, Moline, IL) equipped with a kernel processor set at approximately 6.35 $\mathrm{mm}$. The cutterhead of the harvester used 16 knives (maximum capacity is 48 knives) with the length-of-cut transmission at its highest setting to produce a theoretical length of cut of $47.1 \mathrm{~mm}$. After harvesting, corn silage was ensiled in an Ag-Bag (Ag-Bag, St. Nazianz, WI) and allowed to ferment for $62 \mathrm{~d}$ before beginning the study. Corn silage that was removed from the AgBag and mixed into TMR without further processing was considered LCSLG. A cut-and-throw type, singlerow forage harvester that was modified to operate on a trailer and be fed manually with a 25 horsepower VTwin small gas engine was used to reduce the particle size of corn silage to produce SCSLG. Corn silage was rechopped twice through the custom forage chopper on a daily basis to minimize the chemical variance between LCSLG and SCSLG. Dry corn was ground through a Roskamp roller mill (California Pellet Mill Co., Crawfordsville, IN) to produce the CC used in this study. This corn was then ground further with a Case International 1250 grinder-mixer (Case IH, Racine, WI) using a $3.18-\mathrm{mm}$ screen to produce FC. Diets were mixed 
separately using an I. H. Rissler model 1050 TMR mixer (E. Rissler Mfg. LLC, New Enterprise, PA).

The 4 consecutive days immediately following the adaptation period ( $\mathrm{d} 8$ to 11 ) were designated the baseline for feed preference and rumen conditions. On d 12, feed intakes for each diet were restricted to $75 \%$ of baseline intake. Following feed restriction on d 13 at 0745 h, 4 $\mathrm{kg}$ (as fed) of fine ground wheat was thoroughly mixed into the rumen digesta of each cow via the rumen cannulas to provide a rumen challenge by initiating SARA. Each cow was then allowed ad libitum access to both diets at $0800 \mathrm{~h}$, the amount of TMR offered allowed for approximately $115 \%$ of total daily baseline intake to be consumed from either diet offered. Ad libitum TMR feeding continued on d 14 and 15 to monitor recovery from the rumen challenge.

Animals were housed in individual stalls, milked twice per day at 0500 and $1700 \mathrm{~h}$, and fed once per day at approximately $0800 \mathrm{~h}$ for ad libitum consumption. Cows were fed for a 10\% refusal rate except when either treatment diet intake was below $6 \mathrm{~kg}$ of DM/d, which was set as the minimum amount of feed to be offered to always allow for an opportunity to choose either diet. Feed was pushed up 3 times/d at 1230, 1730, and 2400 h. Rations were balanced to meet or exceed NRC (2001) requirements for cows producing $52.2 \mathrm{~kg}$ of milk/d containing $3.75 \%$ fat and $3.07 \%$ true protein, assuming a DMI of $29.5 \mathrm{~kg} / \mathrm{d}$, and water was available for ad libitum consumption.

\section{Rumen Sampling}

On d 11 of the study, ruminal contents were collected from dorsal, ventral, cranial, caudal, and medial areas of the rumen at $0.0,1.5,3.5,5.5,8.5,11.5,14.5$, 18.0, 21.5, and $24.5 \mathrm{~h}$ after feeding (Kononoff et al., 2003b) to determine baseline rumen conditions. Rumen sampling also occurred on d 12 (feed restriction) at 11.5, 14.5, 18.0, and $21.5 \mathrm{~h}$ after feeding; d 13 (rumen challenge) at $0.0,1.5,3.5,5.5,8.5,11.5,14.5,18.0,21.5$, and $24.5 \mathrm{~h}$ after feeding; and d 14 (recovery) at 3.5, 8.5, 14.5, and $21.5 \mathrm{~h}$ after feeding. At each rumen sampling, collected digesta was mixed thoroughly, sampled, and filtered through 2 layers of cheesecloth. Rumen liquid $\mathrm{pH}$ was immediately determined using a hand-held $\mathrm{pH}$ meter (HI 98121; Hanna Instruments Inc., Woonsocket, RI). Approximately $15 \mathrm{~mL}$ of filtered liquid was placed into bottles containing $3 \mathrm{~mL}$ of $25 \%$ metaphosphoric acid and $3 \mathrm{~mL}$ of $0.6 \%$ 2-ethylbutyric acid (internal standard) and stored at approximately $2^{\circ} \mathrm{C}$. Within 24 $\mathrm{h}$ after collection, samples were centrifuged 3 times at $4000 \times g$ for $30 \mathrm{~min}$ at $4^{\circ} \mathrm{C}$ to obtain a clear supernatant and were analyzed for VFA concentration using gas chromatography (Yang and Varga, 1989).

\section{Feed, Refusal, and Particle Size Analysis}

Feed bunk contents for each animal were weighed and sampled on d 8 to 15 at 0 and $24 \mathrm{~h}$ after feeding to determine particle size distribution and DM content of the remaining feed. Additionally, feed bunk contents were weighed on d 8 to 11 and d 13 at 2, 4, 8 , and $16 \mathrm{~h}$ after feeding. All samples were sieved in duplicate in the American Society of Agriculture and Biological Engineers (ASABE; St. Joseph, MI) forage particle separator, which can determine 6 particle fractions $(>26.9,>18.0,>8.98,>5.61,>1.65$, and $<1.65 \mathrm{~mm}$; screen diagonal; ASABE, 2007). Whole samples were then placed in a forced-air oven at $65^{\circ} \mathrm{C}$ for $48 \mathrm{~h}$ to determine DM content. Samples of forages, ground corn, and TMR were taken on d 11 and 13 and analyzed by Cumberland Valley Analytical Services Inc. (Hagerstown, MD) for CP (AOAC International, 2000), ADF (AOAC International, 2000), NDF (Van Soest et al., 1991), ash (AOAC International, 2000), NFC (Van Soest et al., 1991), and $\mathrm{NE}_{\mathrm{L}}$ (NRC, 2001). Starch contents of forages, ground corn, and TMR were determined by grinding $(0.5-\mathrm{mm}$ screen; Wiley mill; Arthur H. Thomas Co. Inc., Swedesboro, NJ) dried samples and then using the starch procedure reported by Zanton and Heinrichs (2009). Particle size distributions of forages and TMR were determined via sieving with the ASABE forage particle separator (ASABE, 2007). To determine particle size distributions of ground corn, samples were placed on a series of stacked sieves (sizes 0.15, 0.425, 0.60, 0.85, 1.18, $1.70,2.36,3.35,4.75$, and $6.7 \mathrm{~mm}$; VWR, Arlington Heights, IL) contained in a Retsch AS 200 Control sieve shaker (Retsch GmbH, Haan, Germany) and were sieved for $10 \mathrm{~min}$ at $2.5-\mathrm{mm}$ amplitude. There was approximately a $41 \%$ increase between each sieve screen size, except between the 0.15- and $0.425-\mathrm{mm}$ sieves. Particles retained on each sieve were then weighed to determine their proportion of total sample DM. Two procedures were used to calculate physically effective NDF (peNDF) concentration: peNDF $_{8.0}=\%$ of particles $>8.98 \mathrm{~mm} \times \mathrm{NDF}$ concentration of whole sample [similar to top 2 sieves of the Penn State Particle Separator (The Pennsylvania State University)] and $\mathrm{peNDF}_{1.18}=\%$ of particles $>1.65 \mathrm{~mm} \times \mathrm{NDF}$ concentration of whole sample (similar to top 3 sieves of the Penn State Particle Separator; Kononoff et al., 2003a). Corn grain fermentability was determined via in situ bags incubated in quadruplicate in the rumen of 2 lactating cows (each cow incubated 2 bags of each sample for each time point) for $0.5,1,2,4,6,8,12$, 16,24 , and $48 \mathrm{~h}$. After removal from the rumen, bags were rinsed in cold water by hand until the water was almost clear. Bags were then dried in a forced-air oven 
at $65^{\circ} \mathrm{C}$ for $48 \mathrm{~h}$ and then weighed to determine remaining DM.

\section{Statistical Analyses}

Statistical analysis was conducted using PROC MIXED of SAS (version 9.2; SAS Institute Inc., Cary, NC). Dependent variables were analyzed as a crossover design. All denominator degrees of freedom for F-tests were calculated according to Kenward and Roger (1997) and repeated measurements for ruminal $\mathrm{pH}$, ruminal VFA concentrations, and ground corn DM disappearance were analyzed using the first-order autoregressive covariance structure (Littell et al., 1998) as well as terms for time and interaction of treatment by time. Because of unequally spaced rumen sampling, the weighted mean daily $\mathrm{pH}$ and VFA concentrations were determined by calculating the area under the response curve according to the trapezoidal rule (Shipley and Clark, 1972). Area under the curve for the SARA thresholds of 5.8 and 5.5 were also calculated using the trapezoidal rule (Shipley and Clark, 1972). For each cow, the 4 baseline $\mathrm{d}(8,9,10$, and 11) were averaged before analysis to provide equal number of observations between baseline and rumen challenge day. A selection index based on refusals was calculated for each of the 6 particle size fractions. This index was calculated as the actual intake of each fraction ( $\mathrm{Y}_{\mathrm{i}}$ to pan), expressed as a percentage of the expected intake. Expected intake of $Y_{i}$ equals intake multiplied by the fraction of $Y_{i}$ in the fed TMR (Leonardi and Armentano, 2003). Values $>1.0$ indicate that cows were sorting for the particle fraction and values $<1.0$ indicate that cows were sorting against the particle fraction. The $95 \%$ confidence limits were used to determine if a selection index was significantly different from 1.0. All data are presented as least squares means and treatment effects are considered significant at $P<0.05$ and a trend at $P<0.10$.

\section{RESULTS AND DISCUSSION}

\section{Chemical Composition and Particle Size Distribution of Diets}

Particle size distributions and chemical compositions of forages used in this study are shown in Table 1. A large difference was observed in particle size distribution between LCSLG and SCSLG. When separated with the ASABE particle separator, LCSLG had many more particles retained on 26.9- and 18.0-mm screens, equal particles on the $8.98-\mathrm{mm}$ screen, and many fewer particles on 5.61- and $1.65-\mathrm{mm}$ screens and the pan than SCSLG. The approximate equivalency of Penn State Particle Separator fractions to the ASABE screens are top $(26.9+18.0 \mathrm{~mm})$, middle $(8.98 \mathrm{~mm})$, lower $(5.61+1.65 \mathrm{~mm})$, and pan (pan). The particle size distribution of alfalfa haylage was similar to SCSLG. Chemical compositions of the corn silages were similar and not practically different despite some statistically significant differences for DM, ADF, NDF, NFC, and $\mathrm{NE}_{\mathrm{L}}$. Sampling error may be responsible for the small differences seen between LCSLG and SCSLG, as they were taken from the same bag each day as a single batch, with part being rechopped as the only difference. Rechopping of corn silage could conceivably increase DM content through increased drying rate. The peNDF measures were, as expected, very different between corn silages, but a much greater difference was observed for $\operatorname{peNDF}_{8.0}$ than for peNDF ${ }_{1.18}$. The LCSLG was 1.81 and 1.15 times greater than SCSLG for peNDF $_{8.0}$ and peNDF $_{1.18}$, respectively.

The particle size distributions, chemical compositions, and rates of disappearance for corn grains used in this study are shown in Table 2. The particle size distributions of $\mathrm{CC}$ and $\mathrm{FC}$ were different at all 11 particle fractions. The greatest differences occurred at screen sizes $2.36 \mathrm{~mm}$ and larger, where CC had $67.4 \%$ and $\mathrm{FC}$ had $5.6 \%$ of particles retained, and at screen sizes $1.18 \mathrm{~mm}$ and smaller, where CC had $18.4 \%$ and FC had $78.2 \%$ of particles retained. The chemical compositions of $\mathrm{CC}$ and $\mathrm{FC}$ were similar and not practically different despite being statistically different in $\mathrm{DM}$ and $\mathrm{CP}$ content. The rates of disappearance of $\mathrm{CC}$ and FC were different at every time point except $48 \mathrm{~h}$ $(P=0.15)$. The greatest differences between $C C$ and FC were in the first $2 \mathrm{~h}$ of incubation, where FC had about 2.1 times more DM disappearance than CC. The disappearance of FC continued to be greater than $\mathrm{CC}$ at each time point (except $48 \mathrm{~h}$ ), but the differences between them decreased with increasing incubation time. These data should be interpreted with caution, as the effect of eating and rumination on ground corn was not a factor in this analysis and it is reasonable to assume that chewing would have a larger effect on CC because of its greater potential for further particle size reduction.

The particle size distributions and chemical compositions of the treatment TMR are shown in Table 3. Each particle fraction was different between $\mathrm{LC}$ and SF; the 4 largest particle fractions $(>26.9,>18.0,>8.98$, and $>5.61 \mathrm{~mm}$ ) were greater for LC, whereas the 2 smallest particle fractions (>1.65 $\mathrm{mm}$ and pan) were greater for SF. The chemical compositions of the TMR were similar and not practically different. The CP, NDF, forage NDF, and starch content of the TMR were approximately $16.3,31.8,21.5$, and $30.1 \%$ of DM, respectively. The peNDF measures were very different between LC and SF diets, with the greatest difference occurring 
Table 1. Chemical compositions and particle size distributions determined with the American Society of Agriculture and Biological Engineers (ASABE; St. Joseph, MI) particle separator for alfalfa haylage and long and short corn silage

\begin{tabular}{|c|c|c|c|c|c|}
\hline \multirow[b]{2}{*}{ Item } & \multirow{2}{*}{$\begin{array}{c}\text { Alfalfa } \\
\text { haylage }\end{array}$} & \multicolumn{4}{|c|}{ Corn silage } \\
\hline & & Long & Short & SEM & $P$-value \\
\hline \multicolumn{6}{|c|}{ Particle size ${ }^{1}$ as-fed $\%$ retained } \\
\hline $26.9 \mathrm{~mm}$ & 1.9 & 12.6 & 0.9 & 0.65 & $<0.01$ \\
\hline $18.0 \mathrm{~mm}$ & 6.0 & 31.3 & 13.2 & 0.54 & $<0.01$ \\
\hline $8.98 \mathrm{~mm}$ & 26.3 & 28.7 & 28.7 & 1.02 & 1.00 \\
\hline $5.61 \mathrm{~mm}$ & 24.0 & 13.7 & 21.7 & 1.95 & 0.04 \\
\hline $1.65 \mathrm{~mm}$ & 31.8 & 11.9 & 26.8 & 1.32 & $<0.01$ \\
\hline Pan & 10.0 & 1.8 & 8.8 & 1.83 & 0.03 \\
\hline \multicolumn{6}{|c|}{ Composition, $\%$ of DM } \\
\hline DM & 46.0 & 39.2 & 40.7 & 0.92 & $<0.01$ \\
\hline $\mathrm{CP}$ & 18.5 & 8.6 & 8.5 & 0.06 & 0.15 \\
\hline $\mathrm{ADF}$ & 36.0 & 20.7 & 19.1 & 0.47 & 0.04 \\
\hline NDF & 46.4 & 34.9 & 32.6 & 0.67 & 0.05 \\
\hline $\operatorname{peNDF}_{8.0}{ }^{2}$ & 15.9 & 25.4 & 14.0 & 0.66 & $<0.01$ \\
\hline $\operatorname{peNDF}_{1.18}{ }^{3}$ & 41.8 & 34.3 & 29.7 & 0.97 & $<0.01$ \\
\hline Ash & 10.4 & 3.1 & 3.2 & 0.11 & 0.49 \\
\hline NFC & 23.3 & 50.2 & 52.8 & 0.72 & 0.05 \\
\hline Starch & 0.77 & 39.7 & 41.4 & 1.61 & 0.49 \\
\hline $\mathrm{NE}_{\mathrm{L}},{ }^{4} \mathrm{Mcal} / \mathrm{kg}$ & 1.36 & 1.73 & 1.78 & 0.01 & 0.05 \\
\hline
\end{tabular}

${ }^{1}$ Approximate equivalency to Penn State Particle Separator (The Pennsylvania State University, University Park): top sieve $(26.9+18.0 \mathrm{~mm})$, middle sieve $(8.98 \mathrm{~mm})$, lower sieve $(5.61+1.65 \mathrm{~mm})$, and pan $(\mathrm{pan})$.

${ }^{2}$ Physically effective $\mathrm{NDF}_{8.0}\left(\mathrm{peNDF}_{8.0}\right)=\%$ of particles $>8.98 \mathrm{~mm} \times \mathrm{NDF}$ concentration of whole sample (similar to top 2 sieves of Penn State Particle Separator; Kononoff et al., 2003a).

${ }^{3}$ Physically effective $\mathrm{NDF}_{1.18}=\%$ of particles $>1.65 \mathrm{~mm} \times \mathrm{NDF}$ concentration of whole sample (similar to top 3 sieves of Penn State Particle Separator; Kononoff et al., 2003a).

${ }^{4} \mathrm{NRC}(2001)$.

with peNDF $_{8.0}$, where LC was 2.12 times higher than SF (13.8 vs. $6.5 \%)$. The LC diet was only 1.30 times higher than $\mathrm{SF}$ for peNDF 1.18 (27.7 vs. $21.3 \%)$.

\section{Rumen Characteristics}

The effect of the rumen challenge model on rumen $\mathrm{pH}$ is shown in Figure 1. On the baseline day, rumen $\mathrm{pH}$ gradually decreased after feeding to a low of 5.61 at $11.5 \mathrm{~h}$ after feeding. Rumen $\mathrm{pH}$ then gradually increased to preprandial levels by $24 \mathrm{~h}$ after feeding. The following day (feed restriction day), rumen $\mathrm{pH}$ was measured starting at $11.5 \mathrm{~h}$ after feeding and rumen $\mathrm{pH}$ was not different from baseline levels at 11.5 and $14.5 \mathrm{~h}$ after feeding. Rumen $\mathrm{pH}$ then increased faster and remained higher than baseline levels for the remainder of the day. The following day (rumen challenge day), ground wheat was mixed into the rumen via the cannulas of all cows 15 min before feeding. Rumen $\mathrm{pH}$, which began at a higher level than baseline, then dropped sharply after feeding until $3.5 \mathrm{~h}$ after feeding and remained constant for $18 \mathrm{~h}$ after feeding. The rumen challenge day rumen $\mathrm{pH}$ had a 3.8-fold larger decrease from feeding to $1.5 \mathrm{~h}$ after feeding and a 6.1 -fold larger decrease from feeding to $3.5 \mathrm{~h}$ after feeding compared with the baseline day rumen $\mathrm{pH}$. Also, the rumen challenge day rumen $\mathrm{pH}$ was lower than the baseline day rumen $\mathrm{pH}$ at 3.5, 5.5, 8.5, and $18.0 \mathrm{~h}$ after feeding. By $21.5 \mathrm{~h}$ after feeding on the rumen challenge day, the rumen $\mathrm{pH}$ had returned to baseline levels and stayed at baseline levels for the remainder of the rumen challenge day and the following recovery day, except at $21.5 \mathrm{~h}$ after feeding on the recovery day; the cause of this difference is not apparent.

Ruminal $\mathrm{pH}$ daily weighted average was lower and the area under ruminal $\mathrm{pH} 5.8$ and 5.5 was greater during the rumen challenge day compared with baseline (Table 4). This indicates that the rumen challenge was successful in inducing SARA and the decrease in average rumen $\mathrm{pH}$ (0.25-unit decrease) was comparable to other studies attempting to induce SARA in dairy cattle, such as Keunen et al. (2002) and Dohme et al. (2008), with 0.14- and 0.35-unit decreases, respectively. The area under ruminal $\mathrm{pH}$ of 5.8 was increased by 5 fold (50.9 to $254.8 \mathrm{pH}$ units $\times \mathrm{min} / \mathrm{d}$ ) on the rumen challenge day and the area under ruminal $\mathrm{pH}$ of 5.5 was essentially 0.0 during baseline but increased to $37.3 \mathrm{pH}$ units $\times \mathrm{min} / \mathrm{d}$ on the rumen challenge day. Dohme et al. (2008) showed similar areas under the curve for their early-lactation cows subjected to rumen challenges, where areas under 5.8 ruminal $\mathrm{pH}$ were 136,231 , and $475 \mathrm{pH}$ units $\times \mathrm{min} / \mathrm{d}$ and under 5.5 ruminal $\mathrm{pH}$ were 42,91 , and $291 \mathrm{pH}$ units $\times \mathrm{min} / \mathrm{d}$ 
Table 2. Chemical compositions, particle size distributions, and rates of disappearance determined via in situ incubation for dry cracked corn, dry fine ground corn, and ground wheat

\begin{tabular}{|c|c|c|c|c|c|}
\hline \multirow[b]{2}{*}{ Item } & \multirow{2}{*}{$\begin{array}{l}\text { Ground } \\
\text { wheat }\end{array}$} & \multicolumn{4}{|c|}{ Ground corn } \\
\hline & & Cracked & Fine & SEM & $P$-value ${ }^{1}$ \\
\hline \multicolumn{6}{|c|}{ Particle size, as-fed $\%$ retained } \\
\hline $6.70 \mathrm{~mm}$ & 0.0 & 2.2 & 0.0 & 0.18 & $<0.01$ \\
\hline $4.75 \mathrm{~mm}$ & 0.0 & 10.0 & 0.1 & 1.38 & $<0.01$ \\
\hline $3.35 \mathrm{~mm}$ & 0.3 & 29.7 & 0.3 & 1.51 & $<0.01$ \\
\hline $2.36 \mathrm{~mm}$ & 9.3 & 25.5 & 5.2 & 1.29 & $<0.01$ \\
\hline $1.70 \mathrm{~mm}$ & 25.9 & 14.2 & 16.2 & 1.22 & 0.05 \\
\hline $1.18 \mathrm{~mm}$ & 22.9 & 6.5 & 17.7 & 0.54 & $<0.01$ \\
\hline $0.85 \mathrm{~mm}$ & 12.7 & 3.2 & 13.3 & 0.29 & $<0.01$ \\
\hline $0.60 \mathrm{~mm}$ & 7.9 & 2.7 & 11.0 & 0.33 & $<0.01$ \\
\hline $0.425 \mathrm{~mm}$ & 5.5 & 2.0 & 11.4 & 0.80 & $<0.01$ \\
\hline $0.15 \mathrm{~mm}$ & 8.9 & 3.0 & 22.3 & 0.78 & $<0.01$ \\
\hline Pan & 6.7 & 1.0 & 2.5 & 0.22 & 0.01 \\
\hline \multicolumn{6}{|c|}{ Composition, $\%$ of DM } \\
\hline $\mathrm{DM}$ & 86.4 & 90.3 & 88.3 & 0.36 & 0.03 \\
\hline $\mathrm{CP}$ & 11.7 & 8.8 & 9.4 & 0.16 & 0.04 \\
\hline $\mathrm{ADF}$ & 4.4 & 5.1 & 4.4 & 0.38 & 0.27 \\
\hline NDF & 14.1 & 11.3 & 11.1 & 0.52 & 0.77 \\
\hline Ash & 1.5 & 1.4 & 1.6 & 0.12 & 0.31 \\
\hline $\mathrm{NFC}$ & 71.0 & 75.1 & 74.7 & 0.94 & 0.75 \\
\hline $\mathrm{NE}_{\mathrm{L}}, \mathrm{Mcal} / \mathrm{kg}$ & 2.27 & 1.96 & 1.96 & 0.00 & 1.00 \\
\hline \multicolumn{6}{|c|}{ Rate of disappearance. ${ }^{2} \%$} \\
\hline $0.5 \mathrm{~h}$ & - & 17.7 & 36.1 & 2.96 & $<0.01$ \\
\hline $1.0 \mathrm{~h}$ & - & 18.4 & 38.3 & 2.96 & $<0.01$ \\
\hline $2.0 \mathrm{~h}$ & - & 19.0 & 42.0 & 2.96 & $<0.01$ \\
\hline $4.0 \mathrm{~h}$ & - & 27.6 & 48.8 & 2.96 & $<0.01$ \\
\hline $6.0 \mathrm{~h}$ & - & 34.2 & 58.2 & 2.96 & $<0.01$ \\
\hline $8.0 \mathrm{~h}$ & - & 41.9 & 65.8 & 2.96 & $<0.01$ \\
\hline $12.0 \mathrm{~h}$ & - & 56.1 & 76.9 & 2.96 & $<0.01$ \\
\hline $16.0 \mathrm{~h}$ & - & 59.1 & 83.8 & 2.96 & $<0.01$ \\
\hline $24.0 \mathrm{~h}$ & - & 76.4 & 92.0 & 2.96 & $<0.01$ \\
\hline $48.0 \mathrm{~h}$ & - & 90.7 & 96.2 & 2.96 & 0.15 \\
\hline
\end{tabular}

${ }^{1} P$-values express differences between cracked corn and ground corn.

${ }^{2}$ Nylon bags were incubated in quadruplicate in the rumen of 2 lactating cows (each cow incubated 2 bags of each sample for each time point).

(during the first, second, and third rumen challenge, respectively). In addition, more variation was observed in rumen $\mathrm{pH}$ on the rumen challenge day, as it had a lower minimum (5.28 vs. 5.59$)$ and a higher maximum (6.95 vs. 6.69) over $24 \mathrm{~h}$. Rumen VFA concentrations were also determined to be different between these $2 \mathrm{~d}$. The daily weighted average concentration for acetate, butyrate, valerate, and isobutyrate, as well as acetateto-propionate ratio increased on the rumen challenge day. Propionate and isovalerate concentrations were not affected by the rumen challenge, which was unexpected and is unexplained. Khafipour et al. (2009a), using a similar grain-based SARA challenge, had similar shifts in rumen $\mathrm{pH}$ and a decrease in acetate and an increase in propionate and other VFA, as would be expected. In a similar study using alfalfa pellets to induce SARA (Khafipour et al. (2009b), the authors found that all VFA increased again, with similar decreases in rumen $\mathrm{pH}$ over the experiment. In their study, the diet change was more related to forage particle size (replacing alfalfa hay with alfalfa pellets) and also a result of increasing DMI as more pellets were added to the diets.

\section{TMR Preference, DMI, and Refusals}

The TMR preference was measured as the amount of LC diet DM consumed divided by total daily DMI and expressed as a percentage. The average LC consumption for all cows over the 4 baseline days was $18.1 \%$ of total daily DMI (Figure 2). This ratio remained the same for the feed restriction day, as both diets were restricted to $75 \%$ of baseline intake and there were virtually no ration refusals for either diet (Table 5). These results are in agreement with the results of Castle et al. (1979), where 3 grass silages of different particle lengths were fed simultaneously to 3 pregnant Ayrshire heifers. The heifers consumed 15.9, 31.9, and $52.2 \%$ of total DMI as long, medium, and short silages, respectively. After the rumen challenge, LC intake increased dramatically to $38.3 \%$, followed by $28.0 \%$ on the first recovery day. 


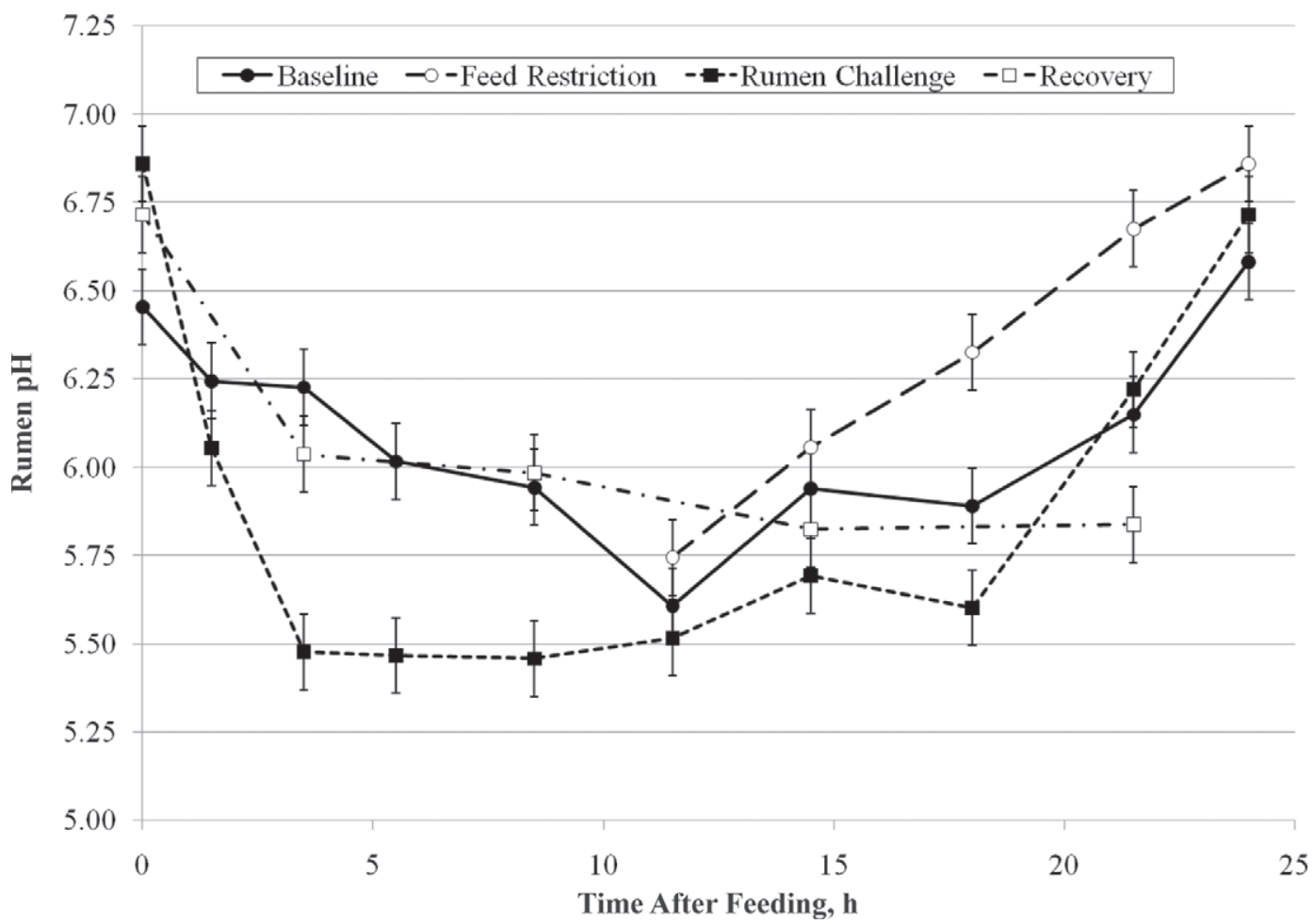

Figure 1. Effect of rumen challenge while offering 2 free-choice TMR containing long forage and slowly fermentable starch or short forage and rapidly fermentable starch on rumen $\mathrm{pH}$ over time for baseline, feed restriction, rumen challenge, and recovery days.

Table 3. Chemical composition and particle size distributions determined with the American Society of Agriculture and Biological Engineers (ASABE; St. Joseph, MI) particle separator for TMR containing long forage and slowly fermentable starch (LC) or short forage and rapidly fermentable starch (SF)

\begin{tabular}{|c|c|c|c|c|}
\hline \multirow[b]{2}{*}{ Item } & \multicolumn{2}{|c|}{ TMR } & \multirow[b]{2}{*}{ SEM } & \multirow[b]{2}{*}{$P$-value } \\
\hline & $\mathrm{LC}$ & $\mathrm{SF}$ & & \\
\hline \multicolumn{5}{|c|}{ Particle size ${ }^{1}$ as-fed $\%$ retained } \\
\hline $26.9 \mathrm{~mm}$ & 3.2 & 0.7 & 0.10 & $<0.01$ \\
\hline $18.0 \mathrm{~mm}$ & 15.0 & 4.3 & 0.26 & $<0.01$ \\
\hline $8.98 \mathrm{~mm}$ & 19.9 & 17.3 & 0.32 & $<0.01$ \\
\hline $5.61 \mathrm{~mm}$ & 22.0 & 18.0 & 1.08 & 0.04 \\
\hline $1.65 \mathrm{~mm}$ & 24.2 & 32.6 & 0.64 & $<0.01$ \\
\hline Pan & 15.6 & 27.2 & 1.53 & 0.01 \\
\hline \multicolumn{5}{|c|}{ Composition, $\%$ of DM } \\
\hline DM, \% & 50.1 & 50.7 & 0.49 & 0.26 \\
\hline $\mathrm{CP}$ & 16.4 & 16.1 & 0.36 & 0.54 \\
\hline $\mathrm{ADF}$ & 20.8 & 19.1 & 0.42 & 0.04 \\
\hline NDF & 32.8 & 30.7 & 0.64 & 0.06 \\
\hline Forage NDF & 21.8 & 21.1 & 0.42 & 0.19 \\
\hline $\operatorname{peNDF}_{8.0}^{2}$ & 13.8 & 6.5 & 0.88 & $<0.01$ \\
\hline $\operatorname{peNDF}_{1.18}{ }^{3}$ & 27.7 & 21.3 & 0.76 & $<0.01$ \\
\hline Ash & 6.6 & 6.1 & 0.18 & 0.03 \\
\hline NFC & 41.0 & 44.2 & 0.32 & $<0.01$ \\
\hline Starch & 28.9 & 31.3 & 0.89 & 0.04 \\
\hline $\mathrm{NE}_{\mathrm{L}},{ }^{4} \mathrm{Mcal} / \mathrm{kg}$ & 1.68 & 1.70 & 0.01 & 0.10 \\
\hline
\end{tabular}

${ }^{1}$ Approximate equivalency to Penn State Particle Separator (The Pennsylvania State University, University Park): top sieve $(26.9+18.0 \mathrm{~mm})$, middle sieve $(8.98 \mathrm{~mm})$, lower sieve $(5.61+1.65 \mathrm{~mm})$, and pan $(\operatorname{pan})$.

${ }^{2}$ Physically effective $\mathrm{NDF}_{8.0}\left(\mathrm{peNDF}_{8.0}\right)=\%$ of particles $>8.98 \mathrm{~mm} \times$ NDF concentration of whole sample (similar to top 2 sieves of Penn State Particle Separator; Kononoff et al., 2003a).

${ }^{3}$ Physically effective $\mathrm{NDF}_{1.18}=\%$ of particles $>1.65 \mathrm{~mm} \times \mathrm{NDF}$ concentration of whole sample (similar to top 3 sieves of Penn State Particle Separator; Kononoff et al., 2003a).

${ }^{4}$ NRC (2001). 
Table 4. Effect of rumen challenge while offering 2 free-choice TMR containing long forage and slowly fermentable starch or short forage and rapidly fermentable starch on rumen $\mathrm{pH}$ and VFA for the baseline and rumen challenge day

\begin{tabular}{|c|c|c|c|c|}
\hline Item & Baseline & Challenge & SEM & $P$-value \\
\hline \multicolumn{5}{|l|}{ Rumen pH } \\
\hline Weighted average ${ }^{1}$ & 6.02 & 5.77 & 0.04 & $<0.01$ \\
\hline Minimum & 5.59 & 5.28 & 0.06 & $<0.01$ \\
\hline Maximum & 6.69 & 6.95 & 0.10 & $<0.01$ \\
\hline $\mathrm{AUC}^{2}<5.8, \mathrm{pH}$ units $\times \min / \mathrm{d}$ & 50.85 & 254.83 & 24.31 & $<0.01$ \\
\hline AUC $<5.5, \mathrm{pH}$ units $\times \min / \mathrm{d}$ & 0.11 & 37.22 & 7.81 & $<0.01$ \\
\hline \multicolumn{5}{|l|}{ VFA weighted average, $\mu \mathrm{mol} / \mathrm{mL}$} \\
\hline Total & 143.45 & 150.35 & 3.89 & 0.07 \\
\hline Acetate & 81.78 & 86.50 & 1.42 & $<0.01$ \\
\hline Propionate & 38.39 & 36.97 & 3.24 & 0.39 \\
\hline Butyrate & 15.00 & 17.90 & 0.57 & $<0.01$ \\
\hline Valerate & 2.69 & 2.90 & 0.38 & 0.01 \\
\hline Isovalerate & 2.25 & 2.30 & 0.11 & 0.53 \\
\hline Isobutyrate & 1.05 & 1.20 & 0.04 & 0.01 \\
\hline Acetate:propionate & 2.29 & 2.58 & 0.25 & 0.03 \\
\hline
\end{tabular}

${ }^{1}$ Weighted averages determined by calculating the area under the response curve according to the trapezoidal rule (Shipley and Clark, 1972).

${ }^{2} \mathrm{AUC}=$ area under curve [area below $\mathrm{pH}$ threshold (5.5 or 5.8 ) and above $\mathrm{pH}$ profiles of cows].

On the second recovery day after rumen challenge, LC intake returned to baseline levels at $18.6 \%$ of total daily DMI. Their results clearly show that the cows very consistently (small SE values) changed their TMR preference in response to a rumen challenge and also they appeared to fully recover from this rumen challenge within $72 \mathrm{~h}$.

The DMI and refusals for each diet for the baseline, feed restriction, rumen challenge, and recovery days are shown in Table 5. The average daily DMI during the baseline period was $30.7 \mathrm{~kg} / \mathrm{d}(5.3$ and $25.4 \mathrm{~kg} / \mathrm{d}$ for

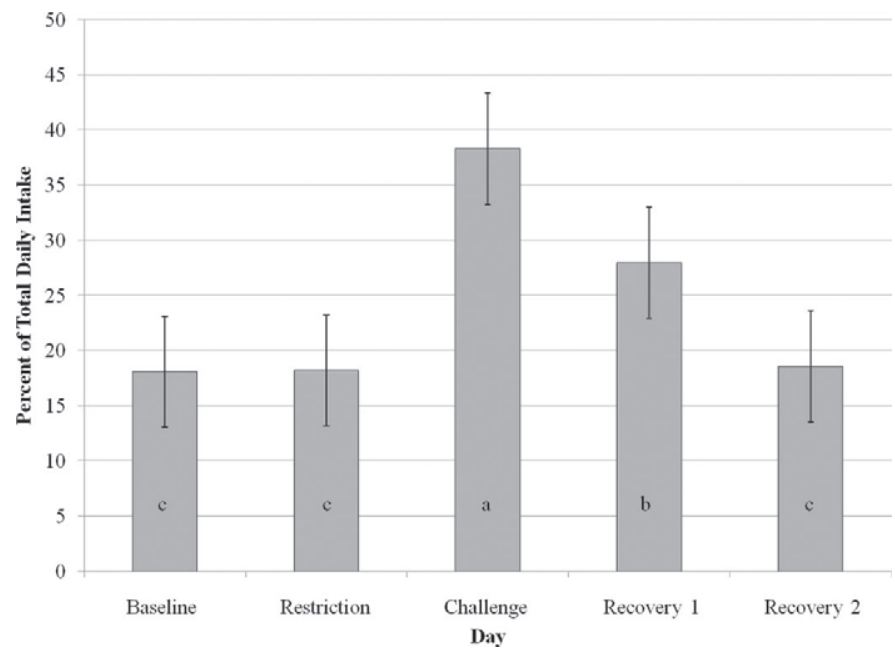

Figure 2. Effect of rumen challenge while offering 2 free-choice TMR containing long forage and slowly fermentable starch or short forage and rapidly fermentable starch on preference for TMR with long forage (expressed as a percentage of total daily intake). Means with different letters $(\mathrm{a}-\mathrm{c})$ differ $(P \leq 0.05)$.
LC and SF, respectively). The following day, feed was restricted to $75.9 \%$ of baseline intake at $23.3 \mathrm{~kg} / \mathrm{d}(4.0$ and $19.3 \mathrm{~kg} / \mathrm{d}$ for $\mathrm{LC}$ and $\mathrm{SF}$, respectively). Rumen challenge day DMI increased from the baseline for LC by $136 \%$ and decreased for SF by $20 \%$ for a total daily intake of $32.7 \mathrm{~kg} / \mathrm{d}$ (excluding ground wheat). Intake of LC recovered to baseline levels by recovery d 1 and SF DMI recovered to baseline levels by recovery $\mathrm{d} 2$. The amount of TMR delivered to the cows was adjusted daily to maintain a refusal rate of $10 \%$, with the exception of the restricted intake day before the rumen challenge. However, as the minimum amount of feed offered per diet per day was set at $6 \mathrm{~kg}$ of DM and most cows consumed less than this amount of the LC diet, LC refusals were much higher than SF refusals during the baseline period (31.8 vs. 9.6\%). On the rumen challenge day, a drastic increase in refusals occurred for both diets because cows were offered approximately $115 \%$ of total daily baseline intake for each diet ( $230 \%$ of total daily baseline intake combined), so they had the ability to consume their entire daily intake from only one diet if they preferred. Therefore, LC refusals were $63.0 \%$ and SF refusals were $45.5 \%$ on the rumen challenge day. Refusal rates remained elevated during the 2 recovery days because larger amounts of feed continued to be offered to allow cows to return to their baseline LC:SF intake ratios without the influence of low diet refusals. Whether TMR was delivered on the left or right side of the feed bunk or whether TMR was delivered to the side of the feed bunk that was adjacent to a water bowl did not affect the percentage of LC consumed as a percentage of total daily DMI $(P=0.68$ and 0.63 , respectively) during the baseline period. 
Table 5. Effect of rumen challenge while offering 2 free-choice TMR containing long forage and slowly fermentable starch (LC) or short forage and rapidly fermentable starch (SF) on DMI and refusals for baseline, feed restriction, rumen challenge, and recovery days

\begin{tabular}{lccccc}
\hline & \multicolumn{2}{c}{ DMI, kg } & & \multicolumn{2}{c}{ Refusal, \% } \\
\cline { 2 - 3 } \cline { 5 - 6 } Day $^{1}$ & LC & SF & & LC & SF \\
\hline Baseline & $5.3^{\mathrm{bc}}$ & $25.4^{\mathrm{a}}$ & & $31.8^{\mathrm{c}}$ & $9.6^{\mathrm{d}}$ \\
Feed restriction & $4.0^{\mathrm{c}}$ & $19.3^{\mathrm{c}}$ & & $4.8^{\mathrm{d}}$ & $0.5^{\mathrm{e}}$ \\
Rumen challenge & $12.5^{\mathrm{a}}$ & $20.2^{\mathrm{c}}$ & & $63.0^{\mathrm{a}}$ & $45.5^{\mathrm{a}}$ \\
Recovery 1 & $7.8^{\mathrm{b}}$ & $21.6^{\mathrm{bc}}$ & & $42.7^{\mathrm{bc}}$ & $27.1^{\mathrm{b}}$ \\
Recovery 2 & $5.0^{\mathrm{c}}$ & $23.5^{\mathrm{ab}}$ & & $49.5^{\mathrm{b}}$ & $18.4^{\mathrm{c}}$ \\
SEM & 1.4 & 2.1 & & 5.7 & 3.1 \\
$P$-value & $<0.01$ & $<0.01$ & & $<0.01$ & $<0.01$ \\
\hline
\end{tabular}

${ }^{a}$ Means within a column with different superscripts differ $(P \leq 0.05)$.

${ }^{1}$ No differences in sorting indices were found among the baseline, rumen challenge, and recovery days (all $P$ $>0.10)$.

The cumulative percentages of daily intakes for each diet for the baseline and rumen challenge day are shown in Figure 3. The cows consumed approximately $21.9 \%$ of their total daily intake by $2 \mathrm{~h}$ after feeding and no differences were observed in the cumulative percentages of daily intakes among the diets or days. At $4 \mathrm{~h}$ after feeding the cows consumed an average of $32.1 \%$ of their daily diet intakes; however, some small differences were observed among the diets and days. The SF intake was lower on the baseline day compared with LC and SF intake on the rumen challenge day. By 8 and $16 \mathrm{~h}$ after feeding, the cows had consumed approximately 51.7 and $81.5 \%$, respectively, of daily diet intakes and no differences existed among diets and days. These results show that the cows consumed the diets simultaneously and in the same ratio throughout the day, independent of which day it was. In other words, the cows did not consume a larger proportion of one diet at certain times of the day and a larger proportion of the second diet at another time of day. These data also show how heavily a cows' daily DMI is skewed toward immediately after feeding when only 1 meal is fed per day in an individual stall housing system, even though ample feed was available before feeding based on consistently having high levels of refusal.

\section{Ration Sorting}

Ration sorting was measured via selection indices calculated by comparing TMR particle size distributions at time of feeding to $24 \mathrm{~h}$ after feeding. The selection index uses the actual consumption of a particle fraction divided by the estimated consumption of the particle fraction if no sorting occurred to produce the index value. Index values $>1.0$ indicate sorting for a particle fraction and values $<1.0$ indicate sorting against. No differences were found in sorting indices among the baseline, rumen challenge, and recovery $\mathrm{d}$ (all $P>$ 0.10 ); therefore, all days were averaged (Tables 5 and 6 ). Based on these selection indices, sorting occurred in all 6 particle fractions when cows were fed the LC diet. They sorted against particles retained on the 3 largest screens $(26.9,18.0$, and $8.98 \mathrm{~mm})$ and for particles in the 3 smallest particle fractions $(>5.61,>1.65 \mathrm{~mm}$, and pan). All of the LC sorting indices were different from 1.0 based on their $95 \%$ confidence limits, even though they did not have very large numerical differences. Much less ration sorting occurred on the SF diet, as 4 of the 6 particle fractions had no significant sorting occurring. The cows fed the SF diet did sort against particles retained on the 18.0- and 8.98-mm screens. In addition, the sorting indices for each particle fraction were different between the diets except for the 18.0-mm screen. It is unlikely that the minimal amount of sorting described in this study influenced cow performance and rumen fermentation, because in a previous study by Maulfair et al. (2010), much greater ration sorting activity was found to have no effects on milk production or rumen fermentation patterns. Evidence exists, however (Penner et al., 2010), that a mild episode of SARA may be sufficient to induce rumen epithelial permeability and create a situation to begin acute ruminal acidosis.

\section{CONCLUSIONS}

Lactating cows were given the choice between an $\mathrm{LC}$ diet and an SF diet. Cows were allowed to adapt to this 2-diet feeding scheme until the intake ratio of LC:SF remained constant. Cows were then given a rumen challenge to induce a bout of SARA. Dairy cattle can significantly alter their TMR preference, when faced with SARA, to a diet with increased peNDF and slower starch fermentability that may help alleviate 
Table 6. Effect of offering 2 free-choice TMR containing long forage and slowly fermentable starch (LC) or short forage and rapidly fermentable starch $(\mathrm{SF})$ on mean selection indices ${ }^{1}$ of baseline, rumen challenge, and recovery days $(4 \mathrm{~d})$

\begin{tabular}{|c|c|c|c|c|}
\hline \multirow[b]{2}{*}{ Screen, ${ }^{2} \mathrm{~mm}$} & \multicolumn{2}{|c|}{ TMR } & \multirow[b]{2}{*}{ SEM } & \multirow[b]{2}{*}{$P$-value } \\
\hline & $\mathrm{LC}$ & SF & & \\
\hline 26.9 & 0.78 & $0.98^{3}$ & 0.05 & $<0.01$ \\
\hline 18.0 & 0.85 & 0.90 & 0.03 & 0.21 \\
\hline 8.98 & 0.91 & 0.96 & 0.01 & $<0.01$ \\
\hline 5.61 & 1.03 & $1.00^{3}$ & 0.01 & 0.02 \\
\hline 1.65 & 1.06 & $1.01^{3}$ & 0.01 & $<0.01$ \\
\hline Pan & 1.15 & $1.02^{3}$ & 0.02 & $<0.01$ \\
\hline
\end{tabular}

${ }^{1}$ Values $=1.00$ indicate no sorting, values $<1.00$ indicate sorting against, and values $>1.00$ indicate sorting for. ${ }^{2}$ Approximate equivalency to Penn State Particle Separator (The Pennsylvania State University, University Park): top sieve $(26.9+18.0 \mathrm{~mm})$, middle sieve $(8.98 \mathrm{~mm})$, lower sieve $(5.61+1.65 \mathrm{~mm})$, and pan $(\operatorname{pan})$.

${ }^{3}$ Sorting index is not significantly different from 1.00 based on a $95 \%$ confidence limit.

their acidotic condition. In addition, this study showed that dairy cattle with this severity of a single bout of SARA can fully recover within $72 \mathrm{~h}$ after onset. As cattle were only fed once per day and only subjected to 1 bout of SARA in this study, further research is warranted to evaluate effects of multiple SARA bouts and different feeding times and feeding systems on diet selection.

\section{ACKNOWLEDGMENTS}

Sincere appreciation is extended to Growmark FS LLC (Sangerfield, NY) for generously allowing the use of their modified forage harvester for the duration of this trial. This research was supported in part by agricultural research funds administered by the Pennsylvania Department of Agriculture (Harrisburg).

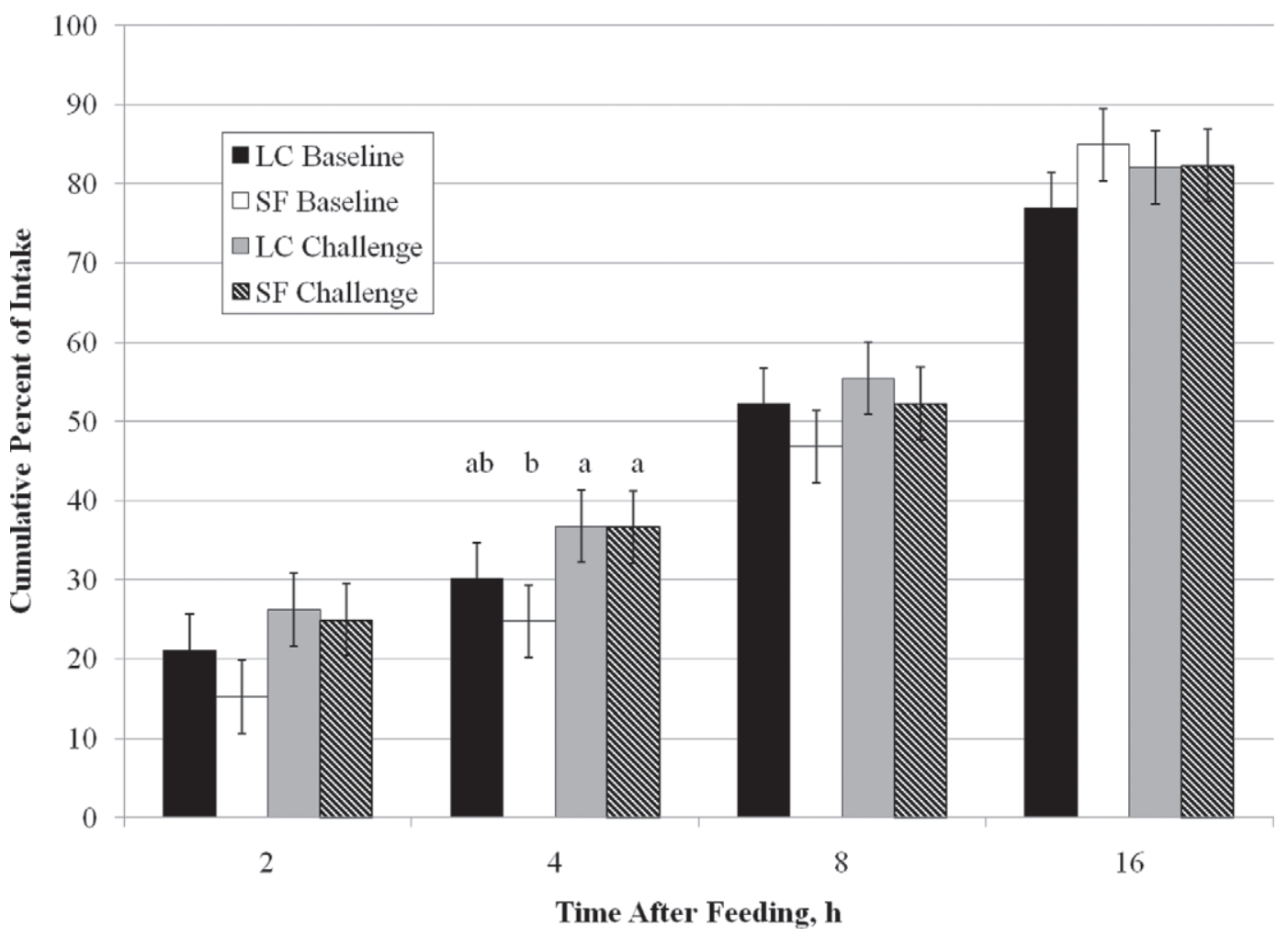

Figure 3. Effect of rumen challenge while offering 2 free-choice TMR containing long forage and slowly fermentable starch (LC) or short forage and rapidly fermentable starch (SF) on cumulative percentage of diet daily intake at various times after feeding for the baseline and rumen challenge day. Means within a time point with different letters (a and b) differ $(P \leq 0.5)$. 


\section{REFERENCES}

AOAC International. 2000. Official Methods of Analysis. 17th ed AOAC International, Arlington, VA.

ASABE (American Society of Agricultural and Biological Engineers). 2007. Method of determining and expressing particle size of chopped forage materials by screening. ANSI/ASAE S424.1:663665. ASABE, St. Joseph, MI.

Britton, R. A., and R. A. Stock. 1987. Acidosis, rate of starch digestion and intake. Pages 125-137 in Symposium Proceedings: Feed Intake by Beef Cattle. F. N. Owens, ed. Oklahoma Agricultural Experiment Station MP-121. Oklahoma State University, Stillwater.

Castle, M. E., W. C. Retter, and J. N. Watson. 1979. Silage and milk production: Comparisons between grass silage of three different chop lengths. Grass Forage Sci. 34:293-301.

DeVries, T. J., F. Dohme, and K. A. Beauchemin. 2008. Repeated ruminal acidosis challenges in lactating dairy cows at high and low risk for developing acidosis: Feed sorting. J. Dairy Sci. 91:3958 3967.

Dohme, F., T. J. DeVries, and K. A. Beauchemin. 2008. Repeated ruminal acidosis challenges in lactating dairy cows at high and low risk for developing acidosis: Ruminal pH. J. Dairy Sci. 91:35543567.

Huntington, G. B. 1993. Nutritional problems related to the gastrointestinal tract. Pages 474-480 in The Ruminant Animal: Digestive Physiology and Nutrition. D. C. Church, ed. Waveland Press Inc., Long Grove, IL.

Kenward, M. G., and J. H. Roger. 1997. Small sample inference for fixed effects from restricted maximum likelihood. Biometrics 53:983-997.

Keunen, J. E., J. C. Plaizier, L. Kyriazakis, T. F. Duffield, T. M. Widowski, M. I. Lindinger, and B. W. McBride. 2002. Effects of a subacute ruminal acidosis model on the diet selection of dairy cows. J. Dairy Sci. 85:3304-3313.

Khafipour, E., D. O. Krause, and J. C. Plaizier. 2009a. A grain-based subacute ruminal acidosis challenge causes translocation of lipopolysaccharide and triggers inflammation. J. Dairy Sci. 92:10601070.

Khafipour, E., D. O. Krause, and J. C. Plaizier. 2009b. Alfalfa pelletinduced subacute ruminal acidosis in dairy cows increases bacterial endotoxin in the rumen without causing inflammation. J. Dairy Sci. 92:1712-1724.

Kononoff, P. J., A. J. Heinrichs, and D. R. Buckmaster. 2003a. Modification of the Penn State forage and total mixed ration particle separator and the effects of moisture content on its measurements. J. Dairy Sci. 86:1858-1863.

Kononoff, P. J., A. J. Heinrichs, and H. A. Lehman. 2003b. The effect of corn silage particle size on eating behavior, chewing activities, and rumen fermentation in lactating dairy cows. J. Dairy Sci. 86:3343-3353

Krause, K. M., and G. R. Oetzel. 2006. Understanding and preventing subacute ruminal acidosis in dairy herds: A review. Anim. Feed Sci. Technol. 126:215-236.

Leonardi, C., and L. E. Armentano. 2003. Effect of quantity, quality, and length of alfalfa hay on selective consumption by dairy cows. J. Dairy Sci. 86:557-564.

Littell, R. C., P. R. Henry, and C. B. Ammerman. 1998. Statistical analysis of repeated measures data using SAS procedures. J. Anim. Sci. 76:1216-1231.

Maulfair, D. D., G. I. Zanton, M. Fustini, and A. J. Heinrichs. 2010 Effect of feed sorting on chewing behavior, production, and rumen fermentation in lactating dairy cows. J. Dairy Sci. 93:4791-4803. NRC. 2001. Nutrient Requirements of Dairy Cattle. 7th rev. ed. Natl. Acad. Sci., Washington, DC.

Nocek, J. E. 1997. Bovine acidosis: Implications on laminitis. J. Dairy Sci. 80:1005-1028

Oetzel, G. R., K. V. Nordlund, and E. F. Garrett. 1999. Effect of ruminal $\mathrm{pH}$ and stage of lactation on ruminal lactate concentration in dairy cows. J. Dairy Sci. 82(Suppl. 1):38. (Abstr.)

Penner, G. B., M. Oba, G. Gabel, and J. R. Aschenbach. 2010. A single mild episode of subacute ruminal acidosis does not affect ruminal barrier function in the short term. J. Dairy Sci. 93:4838-4845.

Phy, T. S., and F. D. Provenza. 1998a. Eating barley too frequently or in excess decreases lambs' preference for barley but sodium bicarbonate and lasalocid attenuate the response. J. Anim. Sci $76: 1578-1583$

Phy, T. S., and F. D. Provenza. 1998b. Sheep fed grain prefer foods and solutions that attenuate acidosis. J. Anim. Sci. 76:954-960.

Shipley, R. A., and R. E. Clark. 1972. Tracer Methods for In Vivo Kinetics. Academic Press, New York, NY.

Stone, W. C. 1999. The effect of subclinical rumen acidosis on milk components. Pages 40-46 in Proceedings of the Cornell Nutrition Conference for Feed Manufacturers, Cornell University, Ithaca, NY.

Stone, W. C. 2004. Nutritional approaches to minimize subacute ruminal acidosis and laminitis in dairy cattle. J. Dairy Sci. 87(E. Suppl.):E13-E26.

Van Soest, P. J., J. B. Robertson, and B. A. Lewis. 1991. Methods for dietary fiber, neutral detergent fiber, and nonstarch polysaccharides in relation to animal nutrition. J. Dairy Sci. 74:3583-3597.

Yang, C.-M. J., and G. A. Varga. 1989. Effect of three concentrate feeding frequencies on rumen protozoa, rumen digesta kinetics, and milk yield in dairy cows. J. Dairy Sci. 72:950-957.

Zanton, G. I., and A. J. Heinrichs. 2009. Digestion and nitrogen utilization in dairy heifers limit-fed a low or high forage ration at four levels of nitrogen intake. J. Dairy Sci. 92:2078-2094. 